\title{
Compliance with antibiotic prophylaxis guidelines in caesarean delivery: a retrospective, drug utilization study (indication-prescription type) at an Ecuadorian hospital
}

\author{
Katherine Romero Viamonte ${ }^{1,2^{*}} \mathbb{D}$, Adrian Salvent Tames ${ }^{3}$, Rosa Sepúlveda Correa ${ }^{4}$,
} María Victoria Rojo Manteca ${ }^{2,5}$ and Ana Martín-Suárez ${ }^{2}$

\begin{abstract}
Background: Preoperative antibiotic prophylaxis is essential for preventing surgical site infection (SSI). The aim of this study was to evaluate compliance with international and local recommendations in caesarean deliveries carried out at the Obstetrics and Gynaecology Service of the Ambato General Hospital, as well as any related health and economic consequences.

Methods: A retrospective indication-prescription drug utilization study was conducted using data from caesarean deliveries occurred in 2018. A clinical pharmacist assessed guidelines compliance based on the following criteria: administration of antibiotic prophylaxis, antibiotic selection, dose, time of administration and duration. The relationship between the frequency of SSI and other variables, including guideline compliance, was analysed. The cost associated with the antibiotic used was compared with the theoretical cost considering total compliance with recommendations. Descriptive statistics, Odds Ratio and Pearson Chi Square were used for data analysis by IBM SPSS Statistics version 25.

Results: The study included 814 patients with an average age of $30.87 \pm 5.50$ years old. Among the caesarean sections, $68.67 \%$ were emergency interventions; $3.44 \%$ lasted longer than four hours and in $0.25 \%$ of the deliveries blood loss was greater than $1.5 \mathrm{~L}$. Only $69.90 \%$ of patients received preoperative antibiotic prophylaxis; however, $100 \%$ received postoperative antibiotic treatment despite disagreement with guideline recommendations (duration: $6.75 \pm 1.39$ days). The use of antibiotic prophylaxis was more frequent in scheduled than in emergency caesarean sections $(\mathrm{OR}=2.79, \mathrm{P}=0.000)$. Nevertheless, the timing of administration, antibiotic selection and dose were more closely adhered to guideline recommendations. The incidence of surgical site infection was $1.35 \%$, but tended to increase in patients who had not received preoperative antibiotic prophylaxis $(\mathrm{OR}=1.33, \mathrm{P}=0.649)$. Also, a significant relationship was found between $\mathrm{SSI}$ and patient age $\left(X^{2}=8.08, \mathrm{P}=0.036\right)$. The mean expenditure on antibiotics per patient was 5.7 times greater than that the cost derived from compliance with international recommendations.
\end{abstract}

Conclusions: Surgical antibiotic prophylaxis compliance was far below guideline recommendations, especially with respect to implementation and duration. This not only poses a risk to patients but leads to unnecessary expenditure

\footnotetext{
*Correspondence: kromeroviamonte@yahoo.es

${ }^{1}$ Faculty of Health Sciences, Technical University of Ambato, Ambato, Ecuador
}

Full list of author information is available at the end of the article

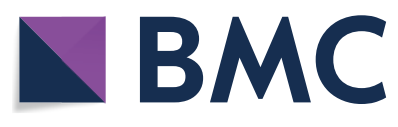

(c) The Author(s) 2021. Open Access This article is licensed under a Creative Commons Attribution 4.0 International License, which permits use, sharing, adaptation, distribution and reproduction in any medium or format, as long as you give appropriate credit to the original author(s) and the source, provide a link to the Creative Commons licence, and indicate if changes were made. The images or other third party material in this article are included in the article's Creative Commons licence, unless indicated otherwise in a credit line to the material. If material is not included in the article's Creative Commons licence and your intended use is not permitted by statutory regulation or exceeds the permitted use, you will need to obtain permission directly from the copyright holder. To view a copy of this licence, visit http://creativecommons.org/licenses/by/4.0/. The Creative Commons Public Domain Dedication waiver (http://creativeco mmons.org/publicdomain/zero/1.0/) applies to the data made available in this article, unless otherwise stated in a credit line to the data. 
on medicines. Therefore, this justifies the need for educational interventions and the implementation of institutional protocols involving pharmacists.

Keywords: Surgical antibiotic prophylaxis, Caesarean section, Surgical site infections, Cost saving, Clinical practice guidelines

\section{Introduction}

Caesarean section is one of the most frequent obstetric surgeries in the world and its use has increased exponentially in recent years [1]; it allows the life of the mother and/or child to be saved in certain situations, but it is not without risk [2].

Complications of caesarean delivery include surgical site infections (SSIs), which are among the leading causes of maternal death [3]. Morbidity from infection has been reported to be about eight times higher after caesarean delivery compared to vaginal delivery, with an SSI rate between 3 and 15\% [4], although according to other studies it may be as high as $25 \%[4,5]$.

Appropriate preoperative antibiotic prophylaxis (PAP), defined by the World Health Organization (WHO) as "administering an effective antimicrobial agent prior to exposure to contamination during surgery", is necessary to prevent SSI [5].

Although multiple studies have shown the importance of the PAP in minimising risks and optimising available institutional resources, recommendations are often not followed [6-8].

In Ecuador, there is a Clinical Practice Guide for Caesarean Delivery Care (CPG-Ecuador) [9] that addresses PAP but does not establish specific protocols for antibiotic use.

Based on the above, the objective of this study is to assess compliance with international and local recommendations on PAP in caesarean delivery at the Obstetrics and Gynaecology Service of Ambato General Hospital as well as its economic impact.

\section{Methods}

A retrospective indication-prescription drug utilization study was conducted. All women who, irrespective of the cause, underwent a caesarean birth in the Obstetrics and Gynaecology Service at the Ambato General Hospital in the year 2018 were considered as the study population. However, some of them were excluded: patients lacking an agreed diagnosis or personal data at the time of the review; patients with Premature Rupture of Membranes (PROM) remote from term (from 24 to 34.6 weeks), as they required another type of prophylaxis not studied in the present study [10]; and patients undergoing antibiotic treatment for an active clinical infection. Thus, the final sample size was 814 patients. The identification of the diagnosis was made in accordance with the International Classification of Diseases, 10th edition (ICD-10).

\section{Information collection}

The information of the patients was obtained from the review of medical records through the file of hospital discharge reports of the Obstetrics and Gynaecology Service from the Medical Information System (MIS/AS400). It included the following data: age, origin, dates of admission and hospital discharge, date and type of surgery (scheduled or emergency), estimated blood loss and SSI.

The following aspects were recorded in relation to PAP: whether or not it was applied, antibiotics used, dose, timing of administration and duration.

\section{PAP compliance assessment}

A clinical pharmacist retrospectively assessed whether preoperative prophylaxis had been adequately used, considering the directives stated in the CPG-Ecuador [9] and the American Society of Health-System Pharmacists (ASHP) Guideline [11]. The following criteria were considered:

\section{PAP indication}

1 Appropriate indication: administering preoperative prophylactic antibiotic treatment before making the skin incision, unless the patient has an active infection for which she is already receiving antibiotic treatment $[9,11]$.

2 Inappropriate indication: when the above is not complied with.

\section{Selection criteria for antibiotics}

1 Appropriate selection of antibiotic: using first generation cephalosporins (cefazolin) or joint treatment of gentamicin and clindamycin in patients allergic to beta-lactams [11].

2 Inappropriate antibiotic selection: using any antibiotic other than those mentioned above. Also included in this category is the use of combination therapies by two or more antibiotics with similar activity spec- 
tra for which there is no evidence demonstrating synergistic activity.

\section{Antibiotic dose}

1 Appropriate dose: cefazolin IV at $2 \mathrm{~g}$ (3 g for patients weighing more than $120 \mathrm{~kg}$ ), clindamycin IV at $900 \mathrm{mg}$ and gentamicin IV at $5 \mathrm{mg} / \mathrm{kg}$ [11].

2 Inappropriate dose: using antibiotics at doses other than those referred to above.

\section{Time of antibiotic prophylaxis}

1 Appropriate timing of administration: receiving the antibiotic intravenously during the $60 \mathrm{~min}$ prior to the surgical incision. In the case of emergency surgery, administration up to the point of incision was considered appropriate $[9,11]$.

2 Inappropriate administration time: receiving an intravenous antibiotic at any other time before or after the incision.

\section{Duration of antibiotic prophylaxis}

1 Appropriate duration: administering a single dose of intravenous antibiotic or, in the case of operations longer than $4 \mathrm{~h}$ or blood loss greater than $1.5 \mathrm{~L}$, prolonging treatment by no more than $24 \mathrm{~h}$ after surgery [11].

2 Inappropriate duration: prolonging the administration of antibiotics for more than $24 \mathrm{~h}$ after the end of surgery.

\section{Cost analysis}

For the cost analysis, only the expenditure associated with the use of antibiotics was taken into account. The unit price of each of the drugs used for PAP was defined based on the information provided by the Pharmacy Department of the institution under study.

The cost of treatment was obtained from the dosage schedule used in each of the patients studied. On the other hand, the ideal cost was calculated considering the compliance with the PAP as established in the reference guidelines and the PAP cost/patient ratio.

The difference between the real cost of the treatments administered and the ideal cost obtained in the research indicates the savings that would have been made by optimising compliance with the recommendations.

\section{Statistical analysis}

IBM SPSS Statistics version 25.0 was used for data analysis. Categorical/Binary variables were presented as frequency and percentage while continuous variables were reported as mean \pm standard deviation. Association between categorical variables was determined using Pearson Chi Square; the Odds Ratio was used to report the statistical association between binary variables. $\mathrm{P}$ value $<0.05$ was considered as statistically significant.

\section{Ethical considerations}

Prior to the start of the study, the protocol was reviewed by the relevant authorities at Ambato General Hospital, who approved the study as meeting the ethical requirements of the institution.

Data analysis was performed in a coded file to preserve patient anonymity.

\section{Results}

Table 1 shows the socio-demographic and clinical characteristics of the 814 patients included in the study. The mean age was $30.87 \pm 5.50$ years, with the majority of patients being between 20-34 years of age. Most of the patients were from urban areas and underwent emergency surgery. The average duration of surgery was $173.54 \pm 46.66 \mathrm{~min}$ and only $3.44 \%$ of the interventions exceeded four hours. In $0.25 \%$ of cases there were blood

Table 1 Sociodemographic and clinical characteristics of the patients included in the study $(n=814)$

\begin{tabular}{lc}
\hline Variables & N (\%) \\
\hline Age (years) & $16(1.97)$ \\
$16-19$ & $584(71.74)$ \\
$20-34$ & $214(26.29)$ \\
$\geq 35$ & \\
Place of origin & $544(66.83)$ \\
Urban & $270(33.17)$ \\
Rural & \\
Type of surgery & $255(31.33)$ \\
Scheduled & $559(68.67)$ \\
Emergency & \\
Duration of surgery (hours) & $786(96.56)$ \\
$<4$ & $28(3.44)$ \\
$\geq 4$ & \\
Blood loss (litres) & $812(99.75)$ \\
$<1.5$ & $2(0.25)$ \\
$\geq 1.5$ & \\
Surgical wound infection & $11(1.35)$ \\
Yes & $803(98.65)$ \\
No &
\end{tabular}


losses of more than $1.5 \mathrm{~L}$, and $1.35 \%$ (11 patients) had SSI. The mean hospital stay was $3.86 \pm 2.59$ days.

Table 2 summarizes the patterns of antibiotic used in the patients studied. $69.90 \%$ were administered PAP using four different therapeutic schemes. The predominant treatment was cefazolin 2 g IV (92.44\%); clindamycin was reserved for patients allergic to penicillin (1.76\%), but in no case was it combined with aminoglycosides, as indicated by ASHP.

All patients received postoperative antibiotics, with a mean duration of $6.75 \pm 1.39$ days. Thus, $88.67 \%$ of them were prescribed parenteral antibiotics during the 24 to $72 \mathrm{~h}$ after surgery following 25 different therapeutic schemes, and in the rest the oral route was used. The most prescribed intravenous antibiotics were cefazolin, clindamycin and ampicillin/sulbactam. After the first 24-72 h, $95.75 \%$ of the patients continued the treatment orally in the form of 21 therapeutic schemes; in nine patients, eight schemes combining oral and parenteral medicines were used. The most prescribed oral antibiotics were cephalexin, clindamycin and amoxicillin/clavulanic acid. Upon discharge from the hospital, the patients received, free of charge, the medicines to complete the treatment.

Table 3 summarises compliance with the recommendations of the selected reference guidelines based on the criteria set out above. Regarding the selection of the antibiotic and dose used, it was not possible to use the CPG-Ecuador because it does not refer to specific drugs or doses.

With regard to costs associated with treatment, which are reflected in Table 4, a total of USD 2743.36 was spent on antibiotic management of patients undergoing caesarean delivery during the study period.

The ideal cost of the PAP, assuming that the recommendations of the ASHP had been followed in all the patients studied, would be USD 476.52. Therefore, compliance would result in savings of USD 2 266,83 (82,63\% of the amount spent). The ideal PAP/patient ratio is 0.59 cents, but the actual average expenditure per patient was USD 3.37, almost six times more than would have been necessary if the protocols had been followed.

Table 2 Use of antibiotics in study patients $(n=814)$

\begin{tabular}{|c|c|c|c|}
\hline \multicolumn{4}{|l|}{ Preoperative administration } \\
\hline $\begin{array}{l}\text { Yes } \\
569(69.90)^{*}\end{array}$ & $\begin{array}{l}\text { No } \\
245(30.10)\end{array}$ & & \\
\hline Administration time & Antibiotic and administered doses & & \\
\hline $\begin{array}{l}\text { Within } 60 \text { minutes before the incision } \\
\text { At the time of incision }\end{array}$ & $\begin{array}{l}212(37.26) \\
357(62.74)\end{array}$ & $\begin{array}{l}\text { Ampicillin/sulbactam } 1.5 \mathrm{~g} \mathrm{IV} \\
\text { Cefazolin } 1 \mathrm{~g} \mathrm{IV} \\
\text { Cefazolin } 2 \mathrm{~g} \mathrm{IV} \\
\text { Clindamycin } 600 \mathrm{mg} \mathrm{IV}\end{array}$ & $\begin{array}{l}1(0.18) \\
32(5.62) \\
526(92.44) \\
10(1.76)\end{array}$ \\
\hline \multicolumn{4}{|l|}{ Postoperative administration } \\
\hline \multicolumn{4}{|l|}{$814(100)$} \\
\hline \multicolumn{4}{|l|}{ Duration of antibiotic treatment } \\
\hline Single dose & - & & \\
\hline $24 \mathrm{~h}$ & - & & \\
\hline$>24 h$ & $814(100)$ & & \\
\hline
\end{tabular}

* Number of patients (\%)

Table 3 Compliance with the recommendations of the reference guidelines for preoperative antibiotic prophylaxis

\begin{tabular}{|c|c|c|c|}
\hline Assessment criteria & & $\begin{array}{l}\text { CPG- Ecuador } \\
\mathrm{N}(\%)\end{array}$ & $\begin{array}{l}\text { ASHP } \\
\text { N (\%) }\end{array}$ \\
\hline \multirow[t]{5}{*}{ Use of PAP } & & $569(69.90)^{*}$ & $569(69.90)^{*}$ \\
\hline & Appropriate selection of the antibiotic & - & $558(98.07)^{* *}$ \\
\hline & Appropriate dose of the antibiotic & - & $526(92.44)^{* *}$ \\
\hline & Appropriate timing of administration & $569(100)^{* *}$ & $569(100)^{* *}$ \\
\hline & Appropriate duration of administration & 0 & 0 \\
\hline
\end{tabular}

CPG-Ecuador Clinical Practice Guidelines for caesarean delivery care in Ecuador, ASHP American Society of Health-System Pharmacists guideline, PAP preoperative antibiotic prophylaxis

*Percentage of the total population included in the study $(n=814)$; **Percentage of the population that received PAP $(n=569)$ 
Table 4 Costs associated with the use of antibiotics in the patients studied

\begin{tabular}{|c|c|c|c|c|c|c|}
\hline \multirow[t]{2}{*}{ PAP assessment criteria } & \multirow[t]{2}{*}{ Patients (N) } & \multicolumn{2}{|c|}{ Pharmaceutical form (Unit) } & \multicolumn{2}{|c|}{ Cost of treatment (USD) } & \multirow{2}{*}{$\begin{array}{l}\text { Global cost } \\
\text { USD (\%) }\end{array}$} \\
\hline & & Capsule & Vial & Capsule & Vial & \\
\hline \multicolumn{7}{|l|}{ Preoperative administration } \\
\hline Appropriate antibiotic selection & 558 & - & 1084 & - & 262.11 & $262.11(9.55)$ \\
\hline Inappropriate antibiotic selection & 11 & - & 11 & - & 18.44 & $18.44(0.67)$ \\
\hline No use of antibiotics & 245 & - & - & - & - & - \\
\hline \multicolumn{7}{|l|}{$\begin{array}{l}\text { Postoperative administration Inap- } \\
\text { propriate }\end{array}$} \\
\hline Unsupported indication & 814 & 23,055 & 4269 & 1033.04 & 1429.77 & $\begin{array}{l}2462.81 \\
(89.78)\end{array}$ \\
\hline Total & 814 & 23,055 & 5364 & 1033.04 & 1710.32 & $2743.36(100)$ \\
\hline
\end{tabular}

\section{Discussion}

Compliance with PAP is an important factor in reducing the incidence of SSI and avoiding the costs associated with it [12]. As in other non-infected surgical acts, antibiotic prophylaxis is recommended for all caesarean deliveries unless the patient is already receiving an antibiotic regimen for another existing infectious entity [9, 11, 13-16]. However, in our study only 569 patients (69.90\%) received PAP.

PAP was administered to a higher percentage of patients in scheduled caesarean Sects. (83.14\%) than in emergency caesarean Sects. (63.83\%) $(\mathrm{OR}=2.79$, $\mathrm{P}=0.000$ ). No data have been found in the literature to corroborate this observation.

Furthermore, all women, including those who did not receive PAP, received post-surgical antibiotic treatment, something which is non-compliant with the guidelines recommendations. This is the most relevant result of the study and is consistent with that obtained by Saied et al. in Egypt [17]. Other studies have also shown the inappropriate duration of PAP and the use of different therapeutic schemes that are poorly described and unnecessary $[7,8,15,18,19]$. Patients who suffered a loss of blood greater than $1.5 \mathrm{~L}$ or who had prolonged surgery (more than $4 \mathrm{~h}$ ), received prophylaxis for approximately 7 days, just like the rest of patients, which is in contradiction to what was stated in the literature $[11,14$, $15]$.

Several studies have shown that there is no significant difference in the incidence of postpartum infectious morbidity between the use of single and multiple doses of PAP [16, 20-23]. The excessive use of antibiotics, could favour the emergence of microbial resistances, increase the risk of adverse reactions and generate unnecessary costs to the institution. The above findings highlight the need for strategies to increase raise the level of practitioner adherence to PAP-use recommendations.
On the other hand,other variables studied showed compliance with the reference guidelines recommendations such as: the timing of administration, the selection of antibiotic and the dose administered (Table 3).

New research continues to recommend that PAP be administered within 60 min before the incision and, in the case of emergency surgery, as soon as possible after the incision, $[8,9,11,16,17]$. In the present study, the timing of PAP administration in all patients was considered appropriate, in contrast to the $80 \%$ non-compliance reported by Abubakar et al. [7].

Antibiotic selection was consistent with ASHP in 98.07\% of patients receiving PAP and the correct drug dose was administered to $94.27 \%$; these results were similar to those obtained by Abdel Jalil et al. [15]. CPGEcuador does not recommend specific antibiotics, which could favour the use of a wide range of therapeutic schemes, as observed in this study.

There is widespread agreement on the use of first generation cephalosporins (cefazolin), or a combination of aminoglycosides and clindamycin for patients with a history of severe reaction to cephalosporins, to avoid SSI in most surgical procedures [11, 24, 25]. However, there are other proposals in terms of antibiotic selection and dosage for PAP in caesarean sections $[16,26$, 27]. The difference could be justified by the characteristics of the circulating germs, the prescribing habits in each institution or the non-existence, inadequate design or non-compliance of clinical guidelines intended for this purpose.

The incidence of SSI in this study (1.35\%) is lower than in other similar studies, where it reaches up to $40 \%$ [19, 28-31]. In patients who were not given PAP, the incidence of SSIs was higher than in those who received pre-surgical antibiotics (1.63\% vs $1.23 \%)$. At the sample level it is observed that the ratio between presence and absence of SSIs is 1.33 times higher in subjects without PAP as compared to subjects with PAP $(\mathrm{OR}=1.33$; 
$\mathrm{P}=0.649)$. This difference increases $(1.14$ vs 1.74$)$ if we compare patients who received the correct antibiotic at the appropriate dose (6 cases in 526) with those who did not receive PAP or who did not receive an appropriate choice of antibiotic and/or dose administered ( 5 cases in 288) $(\mathrm{OR}=1.53, \mathrm{P}=0.485)$. These results may indicate a tendency to decrease the development of SSI when there is greater compliance with the guidelines' recommendations. It should be taken into account, however, that in all patients a post-surgical antibiotic was used for several days, which makes it difficult to statistically demonstrate the benefits of PAP on this variable.

It has also been observed that the incidence of SSIs increases with the age of the patients $(16-19: 0 \% ; 20-34$ : $0.7 \%$; 35 or older: $3.3 \%$ ). Thus, a significant relationship was found between these variables $\left(\chi^{2}=8.08, P=0.036\right)$, which is in line with similar data reported in other studies [31-33]. In contrast, no association was found between patient age and PAP administration $\left(X^{2}=1.59\right.$, $\mathrm{P}=0.44)$.

90.45\% of the expenditure on antibiotics was associated with their inappropriate use, mainly due to their administration after surgery. The ideal PAP cost per patient was 0.59 USD; however, the actual average expenditure per patient was 3.37 USD, i.e. almost six times more (5.7) than needed (Table 4). Although the figures may seem small, the institution has limited capacity for acquiring resources that are indispensable in the health care of other patients.

Unfortunately, little research addresses the issue of costs of noncompliance with the PAP in caesarean sections. Instead, studies generally address the average cost of a patient receiving PAP and how cost-effective it is compared to a patient who does not receive it [32-34]. Jansson et al. found 99\% savings from compliance with the PAP, [35] which is even higher than what was found in the present research.

The participation of the pharmacist within the health care team translates into a decrease in unnecessary costs, an increase in the quality of care and an improvement in the patient's quality of life. These results have led to the acceptance of this professional by other members of the health team [36-41]. To date, there is no clinical pharmacist at the target institution involved in the design, implementation and review of therapeutic protocols, including PAP.

The fact that the study conducted was retrospective is one of its limitations, as it made it difficult to analyse variables that would allow the risks associated with inappropriate duration of antibiotic use to be assessed.

\section{Conclusions}

The study shows a low compliance with the recommendations of the reference guidelines and the general literature in terms of application, selection and duration of antibiotic prophylaxis, which poses a risk to the health of patients and unnecessary expenses for the institution. In addition, it could have a negative effect on public health through increased bacterial resistance.

The analysis of the PAP in the study sample allowed the detection of weaknesses in CPG-Ecuador, which will serve as a basis for the design of institutional preoperative antibiotic prophylaxis policies that clearly detail which antibiotics to use and at what dose, time and duration.

We believe that the intervention of the pharmacist in the process of design, implementation and assessment of PAP protocols could improve the use of antibiotics and their cost effectiveness.

\section{Abbreviations \\ SSIs: Surgical site infections; USD: United States Dollar; PAP: Preoperative antibiotic prophylaxis; WHO: World Health Organization; CPG-Ecuador: Clinical Practice Guidelines for caesarean delivery care in Ecuador; ICD-10: Interna- tional Classification of Diseases, 10th edition; PROM: Premature rupture of membranes; MIS/AS400: Medical Information System; ASHP: American Society of Health-System Pharmacists guidelines.}

\section{Acknowledgements \\ Not applicable.}

\section{Authors' contributions}

All authors contributed to the study design, data analysis, writing and editing of the manuscript. The first two authors also contributed to the acquisition of the data. All authors reviewed and approved the final manuscript.

\section{Funding}

There was no funding for this work.

\section{Availability of data and materials}

The data that support the findings of this study are available from the Obstetrics and Gynaecology Service of the Ambato General Hospital, but restrictions apply to their availability, so they are not publicly available. However, the data may be obtained from the authors upon reasonable request and with the permission of the Obstetrics and Gynaecology Service of Ambato General Hospital.

\section{Ethics approval and consent to participate}

Prior to data collection, approval of the study was sought from the relevant authorities at Ambato General Hospital, who approved the study as meeting the ethical requirements of the institution. Due to the retrospective nature of the work, informed consent is waived.

\section{Consent for publication}

Not applicable.

\section{Competing interests}

The authors declare that they have no conflict of interest.

\section{Author details}

1 Faculty of Health Sciences, Technical University of Ambato, Ambato, Ecuador. ${ }^{2}$ Pharmaceutical Sciences Department, University of Salamanca, Salamanca, Spain. ${ }^{3}$ Obstetrics and Gynaecology Department, Ambato General Hospital, Ambato, Ecuador. ${ }^{4}$ Statistical Department, University of Salamanca, Salamanca, Spain. ${ }^{5}$ Provincial Pharmacists Chamber, Ávila, Spain. 
Received: 25 March 2020 Accepted: 27 October 2020

Published online: 12 January 2021

\section{References}

1. Boerma T, Ronsmans C, Melesse DY, Barros AJD, Barros FC, Juan L, Moller $A B$, et al. Global epidemiology of use of and disparities in caesarean sections. The Lancet. 2018;392(10155):1341-8. https://doi.org/10.1016/S0140 -6736(18)31928-7.

2. World Health Organization. Caesarean sections should only be performed when medically necessary. 2015. https://www.who.int/media centre/news/releases/2015/caesarean-sections/en/. Accessed 20 Mar 2020

3. World Health Organization. Maternal mortality. 2018. https://www.who. int/es/news-room/fact-sheets/detail/maternal-mortality. Accessed 20 Mar 2020

4. Saeed KB, Corcoran P, Greene RA. Incisional surgical site infection following cesarean section: a national retrospective cohort study. Eur J Obstet Gynecol Reprod Biol. 2019;240:256-60. https://doi.org/10.1016/j.ejogr b.2019.07.020

5. World Health Organization. Global Guidelines for the prevention of surgical site infection. 2016. https://apps.who.int/iris/bitstream/handle/10665 /250680/9789241549882-eng.pdf?sequence=8. Accessed 20 Mar 2020

6. Romero Viamonte K, Estrada Cherres JP. Profilaxis antibiótica preoperatoria en pacientes con cirugías ginecológicas en el Hospital "Homero Castanier Crespo." Rev Cubana Obstet Ginecol. 2016;42(4):543-56. http:// scielo.sld.cu/pdf/gin/v42n4/gin15416.pdf.

7. Abubakar U, Syed Sulaiman SA, Adesiyun AG. Utilization of surgical antibiotic prophylaxis for obstetrics and gynaecology surgeries in Northern Nigeria. Int J Clin Pharm. 2018:40(5):1037-43. https://doi.org/10.1007/ s11096-018-0702-0

8. Alemkere G. Antibiotic usage in surgical prophylaxis: A prospective observational study in the surgical ward of Nekemte referral hospital. PLoS ONE. 2018;13(9):e0203523. https://doi.org/10.1371/journal.pone.0203523.

9. Ministerio de Salud Pública del Ecuador. Atención del parto por cesárea. Guía de Práctica Clínica. 2015. http://instituciones.msp.gob.ec/images/ Documentos/GPC_guias_practica_clinica_msp/GPC_atencion_parto _por_cesarea_2015.pdf. Accessed 20 Mar 2020.

10. Ministerio de Salud Pública del Ecuador. Ruptura Prematura de Membranas Pretérmino. Guía de Práctica Clínica. 2015. http://instituciones. msp.gob.ec/images/Documentos/GPC_guias_practica_clinica_msp/ GPC_ruptura_prematura_de_membranas_2015.pdf. Accessed 20 Mar 2020.

11. Bratzler DW, Dellinger EP, Olsen KM, Perl TM, Auwaerter PG, Bolon MK, et al. Clinical practice guidelines for antimicrobial prophylaxis in surgery. Am J Health Syst Pharm. 2013;70(3):195-283. https://doi.org/10.2146/ ajhp120568.

12. Ministerio de Sanidad, Servicios Sociales e Igualdad: Revisión Sistemática de Eventos Adversos y Costes de la No Seguridad. Las infecciones asociadas a la atención sanitaria. España. 2015. https://www.seguridaddelpac iente.es/resources/documentos/2015/COSTES\%20DE\%20LA\%20NO\%20 SEGURIDAD Infecciones.pdf. Accessed 20 Mar 2020

13. Musmar SMJ, Baba H, Owais A. Adherence to guidelines of antibiotic prophylactic use in surgery: a prospective cohort study in a prospective cohort study in North West Bank, Palestine. BMC Surg. 2014;14:69. https:// doi.org/10.1186/1471-2482-14-69.

14. Rodríguez-Caravaca G, Albi-González M, Rubio-Cirilo L, Frías-Aldeguer L, Crispín-Milart PH, VillardelCampo MC. Adecuación de la profilaxis antibiótica en el parto por cesárea. Prog Obstet Ginecol. 2014;57(3):121-5. https://doi.org/10.1016/j.pog.2013.12.002.

15. Abdel Jalil MH, Abu Hammour K, Alsous M, Hadadden R, Awad W, Bakri F, et al. Noncompliance with surgical antimicrobial prophylaxis guidelines: A Jordanian experience in cesarean deliveries. Am J Infect Control. 2018;46(1):14-9. https://doi.org/10.1016/j.ajic.2017.06.033.

16. ACOG Practice Bulletin No. 199. Obstet Gynecol. 2018;132(3):e103-e119. https://doi.org/10.1097/AOG.0000000000002833

17. Saied T, Hafez SF, Kandeel A, El-Kholy A, Ismail G, Aboushady M, et al. Antimicrobial stewardship to optimize the use of antimicrobials for surgical prophylaxis in Egypt: a multicenter pilot intervention study. Am J Infect Control. 2015;43(11):e67-71. https://doi.org/10.1016/j.ajic.2015.07.004.
18. Branch-Elliman W, Pizer SD, Dasinger EA, Gold HS, Abdulkerim H, Rosen AK, et al. Facility type and surgical specialty are associated with suboptimal surgical antimicrobial prophylaxis practice patterns: a multi-center, retrospective cohort study. Antimicrob Resist Infect Control. 2019;8:49. https://doi.org/10.1186/s13756-019-0503-9.

19. Zejnullahu VA, Isjanovska R, Sejfija Z, Zejnullahu VA. Surgical site infections after cesarean sections at the University Clinical Center of Kosovo: rates, microbiological profile and risk factors. BMC Infect Dis. 2019;19(1):752. https://doi.org/10.1186/s12879-019-4383-7.

20. Pinto-Lopes R, Sousa-into B, Azevedo LF. Single dose versus multiple dose of antibiotic prophylaxis in caesarean section: a systematic review and meta-analysis. BJOG. 2017;124(4):595-605. https://doi.org/10.1111/14710528.14373.

21. Westen EHMN, Kolk PR, van Velzen CL, Unkels R, Mmuni NS, Hamisi AD, et al. Single-dose compared with multiple day antibiotic prophylaxis for cesarean section in low-resource settings, a randomized controlled, noninferiority trial. Acta Obstet Gynecol Scand. 2015;94(1):43-9. https:// doi.org/10.1111/aogs.12517.

22. Shaheen S, Akhtar S. Comparison of single dose versus multiple doses of antibiotic prophylaxis in elective caesarian section. J Postgrad Med Inst. 2014;28(1):83-6. http://ejournalsystem.net/index.php/jpmi/article/ view/1478.

23. Berríos Torres SI, Umscheid CA, Bratzler DW, Leas B, Stone EC, Kelz RR, et al. Centers for disease control and prevention guideline for the prevention of surgical site infection, 2017. JAMA Surg. 2017;152(8):784-91. https ://doi.org/10.1001/jamasurg.2017.0904.

24. Zhang C, Zhang L, Liu X, Zhang L, Zeng Z, Li L, et al. Timing of antibiotic prophylaxis in elective caesarean delivery: a multi-center randomized controlled trial and meta-analysis. PLoS ONE. 2015;10(7):e0129434. https ://doi.org/10.1371/journal.pone.0129434.

25. Khlifi A, Kouira M, Bannour I, Hachani F, Kehila M, Ferhi F, et al. What's the optimal time of cesarean section antibiotic prophylaxis, before skin incision or after umbilical cord clamping? A prospective randomized study. J Gynecol Obstet Biol Reprod (Paris). 2016;45(9):1133-43. https://doi. org/10.1016/j.jgyn.2016.03.004.

26. Douville SE, Callaway LK, Amoako A, Roberts J, Eley VA. Reducing postcaesarean delivery surgical site infections: a narrative review. Int J Obstet Anesth. 2020:42:76-6. https://doi.org/10.1016/j.ijoa.2019.08.007.

27. Comité de pilotage Société française d'anesthésie et de réanimation: Antibioprophylaxie en chirurgie et médecine interventionnelle (patients adultes) 2017. https://sfar.org/wp-content/uploads/2018/08/Antibiopro phylaxie-version-2017-CRC CA MODIF.pdf. Accessed 20 Mar 2020

28. Mohan J, Thangaroja T, Menon M. Single dose antibiotic prophylaxis in elective obstetric and gynaecological surgeries-a descriptive study. Int J Reprod Contracept Obstet Gynecol. 2017;6(9):3897-990. https://doi. org/10.18203/2320-1770.ijrcog20174030.

29. Jansson MH, Cao Y, Nilsson K, Larsson PG, Hagberg L. Cost-effectiveness of antibiotic prophylaxis in elective cesarean section. Cost Eff Resour Alloc. 2018;16:66. https://doi.org/10.1186/s12962-018-0168-x.

30. Alfouzan W, Al Fadhli M, Abdo N, Alali W, Dhar R. Surgical site infection following cesarean section in a general hospital in Kuwait: trends and risk factors. Epidemiol Infect. 2019;147:e287. https://doi.org/10.1017/S0950 268819001675

31. Merzougui L, Marwen N, Hannachi H, Asma M, et al. Incidence and risk factors of surgical site infection following caesarean section in a Tunisian maternity unit. Sante Publique. 2018;30(3):339-47. https://doi. org/10.3917/spub.183.033.

32. Smaill FM, Grivell RM. Antibiotic prophylaxis versus no prophylaxis for preventing infection after cesarean section (Review). Cochrane Database Syst Rev. 2014;10:007482. https://doi.org/10.1002/14651858.CD007482. pub2.

33. Gulluoglu BM, Guler SA, Ugurlu MU, Culha G. Efficacy of prophylactic antibiotic administration for breast cancer surgery in overweight or obese patients a randomized controlled trial. Ann Surg. 2013;257(1):37-43. https ://doi.org/10.1097/SLA.0b013e31826d832d.

34. Lewis A, Sen R, Hill TC, James H, Lin J, Bhamra H, et al. Antibiotic prophylaxis for subdural and subgaleal drains. J Neurosurg. 2016;126(3):908-12. https://doi.org/10.3171/2016.4.JNS16275.

35. Henderson J, Redshaw M. Change over time in women's views and experiences of maternity care in England, 1995-2014: a comparison 
using survey data. Midwifery. 2017;44:35-40. https://doi.org/10.1016/j. midw.2016.11.003.

36. Ministers'Deputies. Resolution CM/Res(2020)3 on the implementation of pharmaceutical care for the benefit of patients and health services 2020 . https://rm.coe.int/09000016809cdf26. Accessed 2 Sept 2020.

37. Butt SZ, Ahmad M, Saeed H, Saleem Z, Javaid Z. Post-surgical antibiotic prophylaxis: impact of pharmacist's educational intervention on appropriate use of antibiotics. J Infect Public Health. 2019;12(6):854-60. https:// doi.org/10.1016/j.jiph.2019.05.015

38. Nas Z, Babiker A, Elbashee M, Osman A, Elazzazy S, Wilby KJ. Practice implications of an antimicrobial stewardship intervention in a tertiary care teaching hospital. Qatar East Mediterr Health J. 2019;25(3):172-80. https://doi.org/10.26719/emhj.18.026.

39. Sakeena MHF, Bennett AA, McLachlan AJ. Enhancing pharmacists' role in developing countries to overcome the challenge of antimicrobial resistance: a narrative review. Antimicrob Resist Infect Control. 2018;7:63. https://doi.org/10.1186/s13756-018-0351-z.

40. Nguyen MP, Crotty MP, Daniel B, Dominguez E. An evaluation of guideline concordance in the management of intra-abdominal infections. Surg Infect (Larchmt). 2019;20(8):650-7. https://doi.org/10.1089/sur.2018.317.

41. VanLangen KM, Dumkow LE, Axford KL, Havlichek DH, Baker JJ, Drobish IC, et al. Evaluation of a multifaceted approach to antimicrobial stewardship education methods for medical residents. Infect Control Hosp Epidemiol. 2019;40(11):1236-41. https://doi.org/10.1017/ice.2019.253.

\section{Publisher's Note}

Springer Nature remains neutral with regard to jurisdictional claims in published maps and institutional affiliations.
Ready to submit your research? Choose BMC and benefit from:

- fast, convenient online submission

- thorough peer review by experienced researchers in your field

- rapid publication on acceptance

- support for research data, including large and complex data types

- gold Open Access which fosters wider collaboration and increased citations

- maximum visibility for your research: over $100 \mathrm{M}$ website views per year

At BMC, research is always in progress.

Learn more biomedcentral.com/submissions 